\title{
Atmospheric dispersion modelling over complex terrain at small scale
}

\author{
S. Nosek ${ }^{1, a}, Z_{\text {. Janour }}^{1}$, L. Kukacka ${ }^{1,2}$, K. Jurcakova ${ }^{1}$, R. Kellnerova ${ }^{1,2}$, and E.Gulikova ${ }^{3}$ \\ ${ }^{1}$ Institute of Thermomechanics AS CR, Prague, Czech Republic \\ ${ }^{2}$ Charles University, Department of Meteorology and Environment Protection, Prague, Czech Republic \\ ${ }^{3}$ Ecoprogress, Most, Czech Republic
}

\begin{abstract}
Previous study concerned of qualitative modelling neutrally stratified flow over open-cut coal mine and important surrounding topography at meso-scale (1:9000) revealed an important area for quantitative modelling of atmospheric dispersion at small-scale (1:3300). The selected area includes a necessary part of the coal mine topography with respect to its future expansion and surrounding populated areas. At this small-scale simultaneous measurement of velocity components and concentrations in specified points of vertical and horizontal planes were performed by two-dimensional Laser Doppler Anemometry (LDA) and Fast-Response Flame Ionization Detector (FFID), respectively. The impact of the complex terrain on passive pollutant dispersion with respect to the prevailing wind direction was observed and the prediction of the air quality at populated areas is discussed. The measured data will be used for comparison with another model taking into account the future coal mine transformation. Thus, the impact of coal mine transformation on pollutant dispersion can be observed.
\end{abstract}

\section{Introduction}

The difficulties concerning of atmospheric dispersion modelling above coal mine excavations in wind-tunnels are due to common huge dimensions (several kilometres for its length or width and hundreds meters for its depth). The necessary mine surrounding topography incorporated into the model results in very small scales $(>1: 5000)$. The problems with two-phase flow modeling arise because many similarity criteria for dust emission modeling can't be met (e.g. threshold and terminal velocity ratio). Only the flow modeling over mine excavations in order to understand the airflow patterns was performed during seventies and eighties by Nikitin and Bitkolov [1] and during nineties by Peng and $\mathrm{Lu}$ [2]. Meroney and Grainger [3] were the first who performed not only the atmospheric dispersion of passive pollutant (simulated helium/air tracer gas mixtures releasing from point source) but also the stratified flow over the Australian open-cut coal mine.

In previous work [4] we performed the qualitative modeling method (turbulent-laminar analogy) over the model of open-cut coal mine situated in the north-west part of the Czech Republic at meso-scale (1:9000). The main objective was to simulate main flow field over the mine and its surrounding topography in order to select the appropriate area for future modeling. In this paper we present the results from atmospheric dispersion modeling over the selected area provided similar approach as mentioned in work [3]. Instead of stratified the neutrally stratified flow and ethane as passive pollutant releasing from point source at the bottom of the mine (representing e.g. mining machine) was chosen for simulation.

\section{Methods}

\subsection{Wind tunnel}

The experiment was carried out at open Environmental wind-tunnel of Institute of Thermomechanics Academy of Sciences of the Czech Republic in Nový Knín. The tunnel is $1.5 \mathrm{~m}$ wide and $1.5 \mathrm{~m}$ high and consists of two main sections: $20 \mathrm{~m}$ long section for development of appropriate boundary layer and $2 \mathrm{~m}$ long test section where the measurements above the model are performed. The free stream speed can be maintained from 0.1 up to $13 \mathrm{~m} / \mathrm{s}$. For our case of small scale ratio $(1: 3300)$ the development section was kept empty, without any roughness elements and spires. Only $1.5 \mathrm{~m}$ of special inclination smoothly connected to model relief was kept in development section. This special inclination reproduces topography of coal mine situated in front of the modelled area and was roughen by sand grains (size of the grains was smaller than $0.5 \mathrm{~mm}$ ) in order to achieve aerodynamically rough flow and appropriate characteristics of modeled atmospheric boundary layer.

\footnotetext{
${ }^{\mathrm{a}}$ Corresponding author: nosek@it.cas.cz
} 


\subsection{Model}

In Figure 1 is depicted the model selection area on terrain map including a necessary part of the coal mine topography with respect to future coal mine expansion and surrounding populated areas (south part of town Chomutov, Droužkovice village). The area selected according to wind-tunnel dimensions and previous study [4] resulted in total squared area of approx. $5 \times 5 \mathrm{~km}$ and scale of $1: 3300$.

The model was made of extruded polyurethane and manufactured by computer numerically controlled (CNC) machine with precision of $0.5 \mathrm{~mm}$. The special roughness of $0.5 \mathrm{~mm}$ was applied by $\mathrm{CNC}$ machine for model surface as well as all necessary vegetation and urban areas were made manually for completeness (Figure 2) in order to fulfill the aerodynamic roughness of moderately rough terrain. As input data for $\mathrm{CNC}$ the geographic information system (GIS) was used.

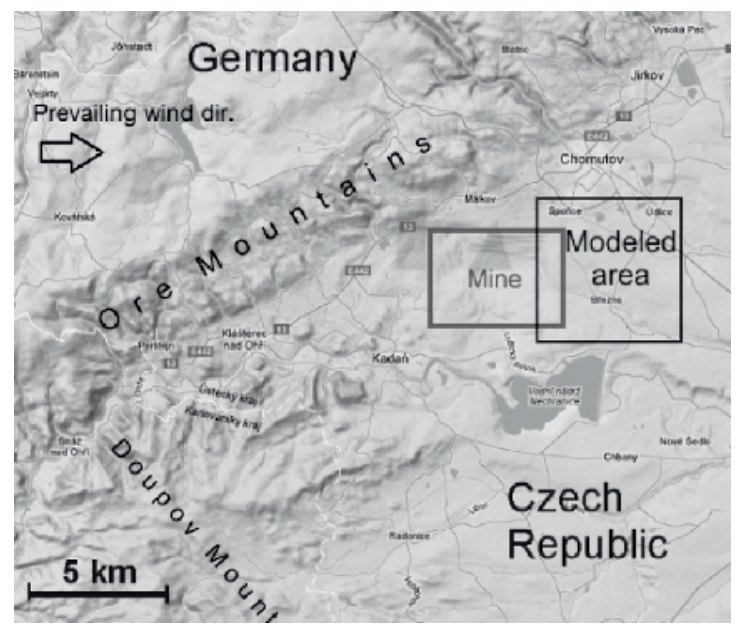

Figure 1. Map of modelled area (square of $5 \mathrm{~km}$ length) with highlighted borders of open-cut coal mine and characteristic orography of north-west part of Czech Republic. The prevailing wind direction is from west.

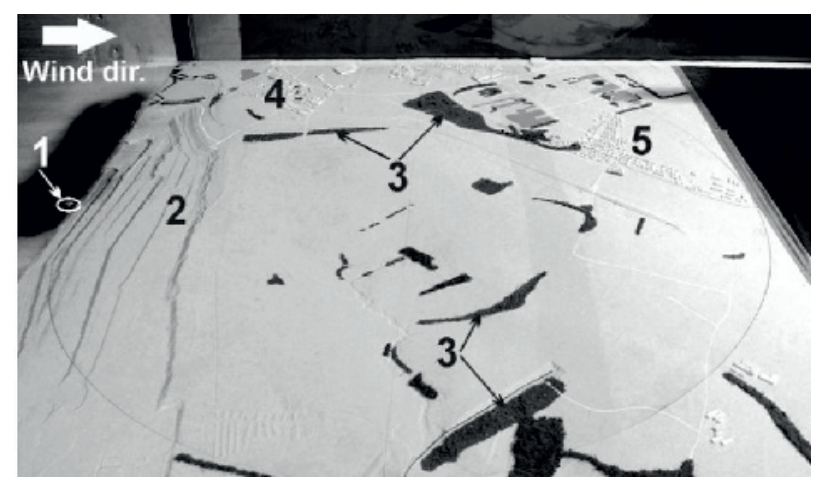

Figure 2. Model of scale ratio 1:3300 positioned at wind-tunnel including point source of pollutant (1) integrated at the bottom of special inclination smoothly connected to east end of coal mine (2), necessary vegetation (3), south part of town Chomutov (4) and village Droužkovice (5).

\subsection{Measurement techniques}

In Figure 3 is presented the unique method used for simultaneous point measurements of two velocity components and concentrations by two-dimensional optical fibre Laser Doppler Anemometry (LDA) and Fast-response Flame Ionization Detector (FFID), respectively, developed by Kukačka [5]. Ethane was used as a tracer gas simulating passive pollutant releasing from point source positioned at the bottom of the coal mine. The wind-tunnel free stream velocity was measured by Prandtl tube at fixed position in the centre of wind-tunnel $3 \mathrm{~m}$ in front of the model and was used as a reference velocity $u_{\text {ref }}$ for point measurements.

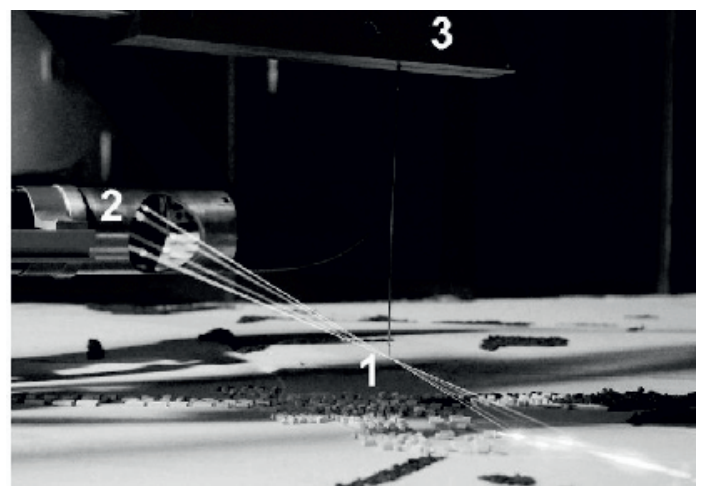

Figure 3. The simultaneous point (1) measurements of two velocity components and concentrations by LDA (2) and FFID (3), respectively, above the model during experiment.

\subsection{Boundary layer}

The required boundary layer substituting the real atmospheric boundary layer over the moderately rough terrain (e.g. moderate hills, forests) was modelled in 19.5 $\mathrm{m}$ long wind-tunnel development section without any roughness elements and vortex generators. Twodimensional LDA measurements in vertical profile was performed above the centre of the special inclination 10 $\mathrm{cm}$ in front of the model connection using a reference wind speed $u_{\text {ref }}=5.2 \mathrm{~m} / \mathrm{s}$.

In Figure 4 are compared the measured vertical profile of dimensionless mean longitudinal velocity $u / u_{\text {ref }}$, turbulence profiles and turbulence spectra of $u$ with profiles from VDI guidelines (Verein Deutscher Ingenieure [6]) for moderately rough terrain. Mean roughness length $z_{0}=0.04 \mathrm{~m}$ (converted to full scale) and power exponent $\alpha=0.13$ was obtained from the log fitting and power fitting, respectively. According to VDI guidelines [6] for moderately rough terrain the $z_{0}$ should be from $5.10^{-3}$ to $10^{-1} \mathrm{~m}$ and $\alpha$ from 0.12 to 0.18 .

The turbulence spectrum was evaluated at four heights of measured vertical velocity profile: $13.5,57$, 100 and $600 \mathrm{~m}$ above the inclination surface. The spectra for height $100 \mathrm{~m}$ were compared with Kaimal, Karman and Simiu\&Scanlan spectra in Figure 4 (right). The best fit of measured spectra is with the Karman spectra for all four heights.

Thus, we could conclude that characteristic boundary layer for moderately rough type of terrain was modelled appropriately. Furthermore, the Reynolds number, averaging time and source strength independence was fulfilled as well. 

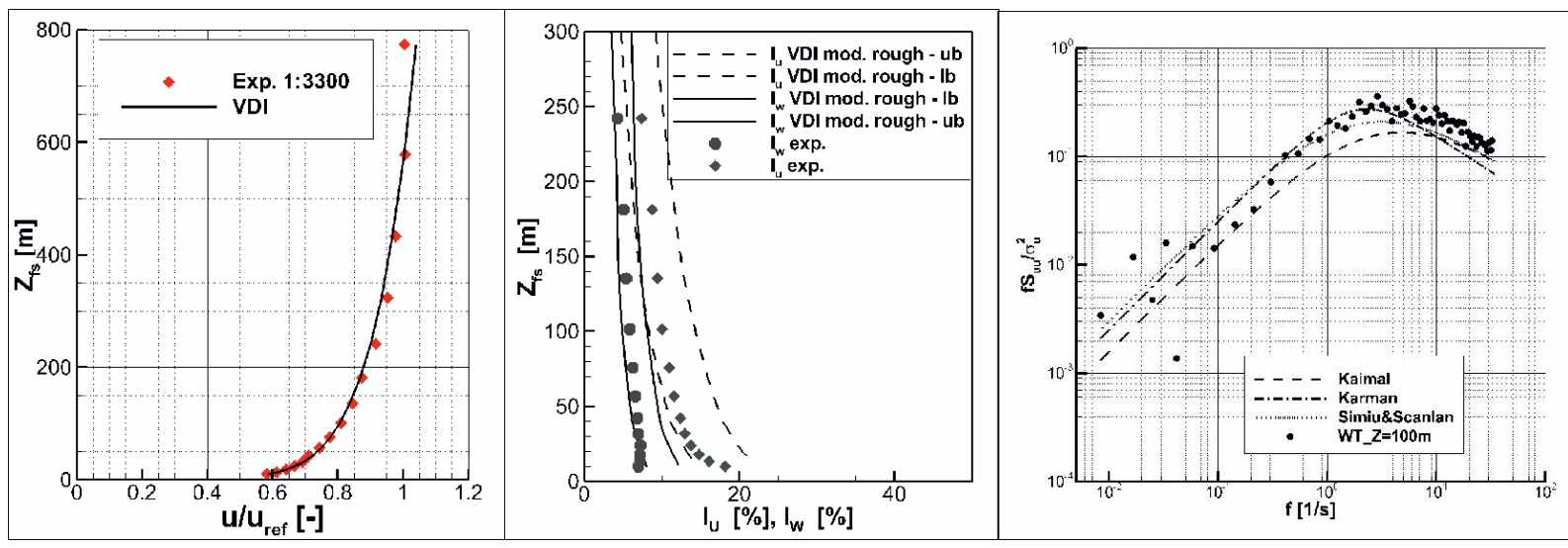

Figure 4. The vertical profile of dimensionless longitudinal velocity $u / u_{\text {ref }}$ (left), vertical profiles of turbulence intensities $I_{u}, I_{w}$ (middle) and longitudinal velocity turbulence spectrum $S_{u u}$ of modelled boundary layer at full scale height $100 \mathrm{~m}$ above the terrain (WT_Z=100) compared with Kaimal, Karman and Simiu\&Scanlan spectra (right).

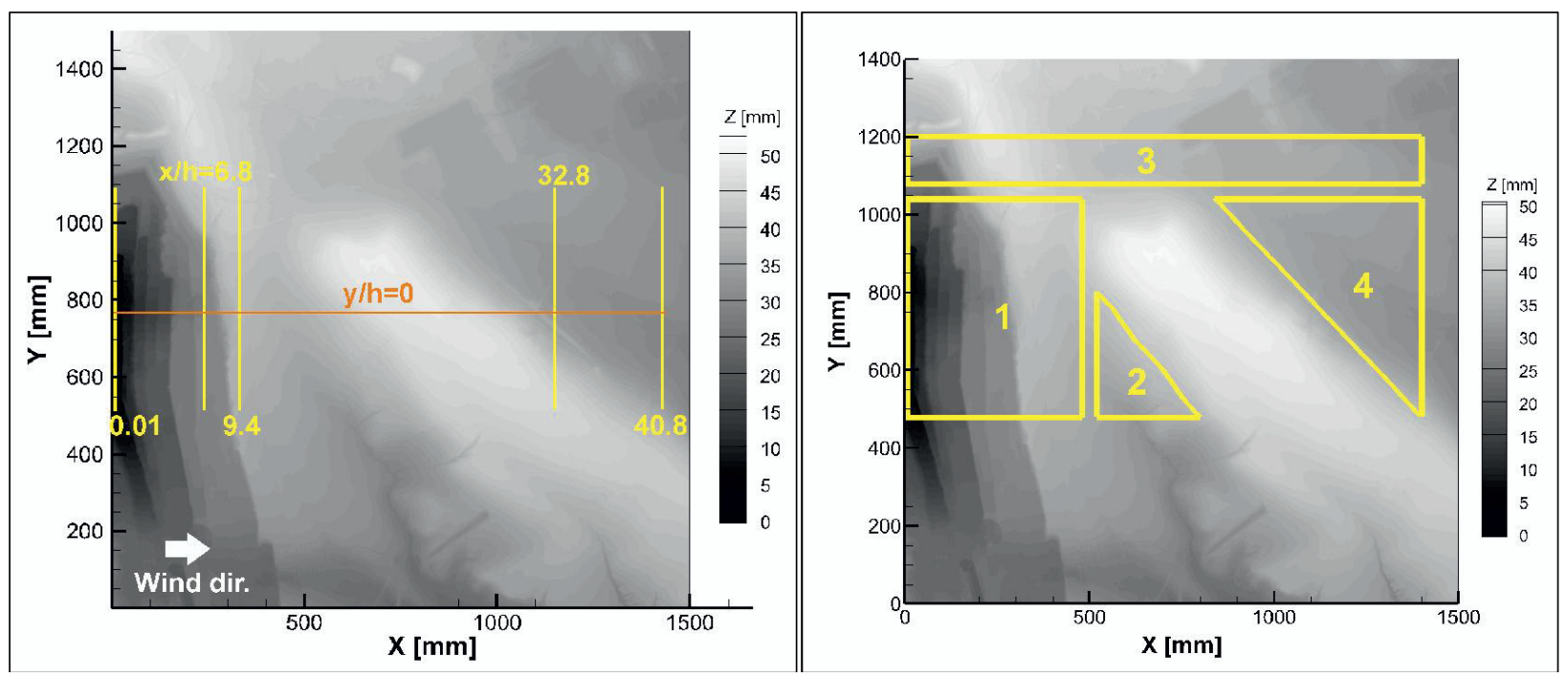

Figure 5. Measured vertical planes $y z$ (vertical lines) and vertical plane $x z$ (horizontal line) displayed on model contour map (left) and horizontal planes $x y$ at dimensionless height $z / h=1.5$ (right). Wind direction is from left to right. Note the elongated hill in the middle of the model (white contours) and cornered coal mine border (top part of the $x y$ plane 1 and the most left part of $x y$ plane 3 ).

\section{Results}

Measured five vertical planes $y z$, one vertical plane $x z$ and four horizontal planes $x y$ are depicted in Figure 5 on the model contour map at dimensionless coordinates $x / h$ and $y / h$, respectively, where $h$ is a coal mine depth $(h=$ $35 \mathrm{~mm}$, corresponding to $115 \mathrm{~m}$ at full scale). The horizontal planes were measured at dimensionless height $z / h=1.5$.

In following sections are presented only selected results from velocity and concentration fileds.

\subsection{Velocity field}

Mean dimensionless longitudinal $u / u_{\text {ref }}$ and vertical $w / u_{\text {ref }}$ velocity fields were measured at both vertical plane $x z$ (Figure 6) and vertical planes $y z$. In Figure 7 are presented only the dimensionless vertical velocity fields. The impact of mine escarpments, hill in the middle of the model and surface roughness (vegetation and urban areas) on both mean velocity fields was observed. The speed up of dimensionless longitudinal velocity is evident at the edges of mine escarpments and top of the hill. Even though the magnitude of dimensionless vertical velocity $w / u_{\text {ref }}$ was rather low the ascending effects (positive values of $\left.w / u_{\text {ref }}\right)$ was found near by the mine escarpments (Figure 6 and 7, $x / h=6.8$ ), upstream the slope of the hill and vegetation and urban areas (Figure $7, x / h=32.8$ and 40.8). The biggest descending effect (negative values of $w / u_{\text {ref }}$ ) occurs downstream the hill (Figure $7, x / h=32.8$ ).

The dimensional longitudinal $u / u_{\text {ref }}$ and lateral $v / u_{r e f}$ velocity fields measured at horizontal planes $x y$ are presented in Figure 8 . The positive values of $v / u_{r e f}$ represent direction to left and negative values direction to right Although the measured height is one and half of the mine depth (approx. $173 \mathrm{~m}$ at full scale) the impact of excavation border on longitudinal and lateral velocity is evident. Especially the lateral velocity field copy the borders of the mine (note the corner in Figure for case

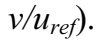

Both longitudinal $I_{u}$ and vertical $I_{w}$ turbulence intensity higher than 20\% (not shown here) correlated with topographic features of the model (e.g. mine escarpments) and with model surface roughness (vegetation, urban areas). 

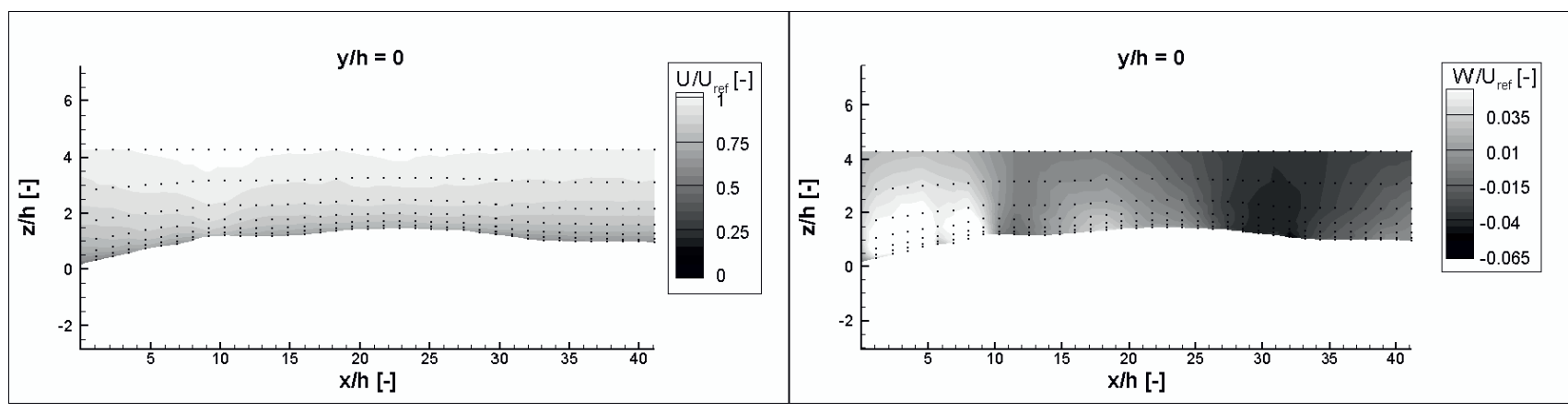

Figure 6. Mean dimensionless longitudinal velocity $u / u_{\text {ref }}$ (left) and dimensionless vertical velocity $w / u_{\text {ref }}($ right $)$ at plane $x y$. The wind direction is from left to right.

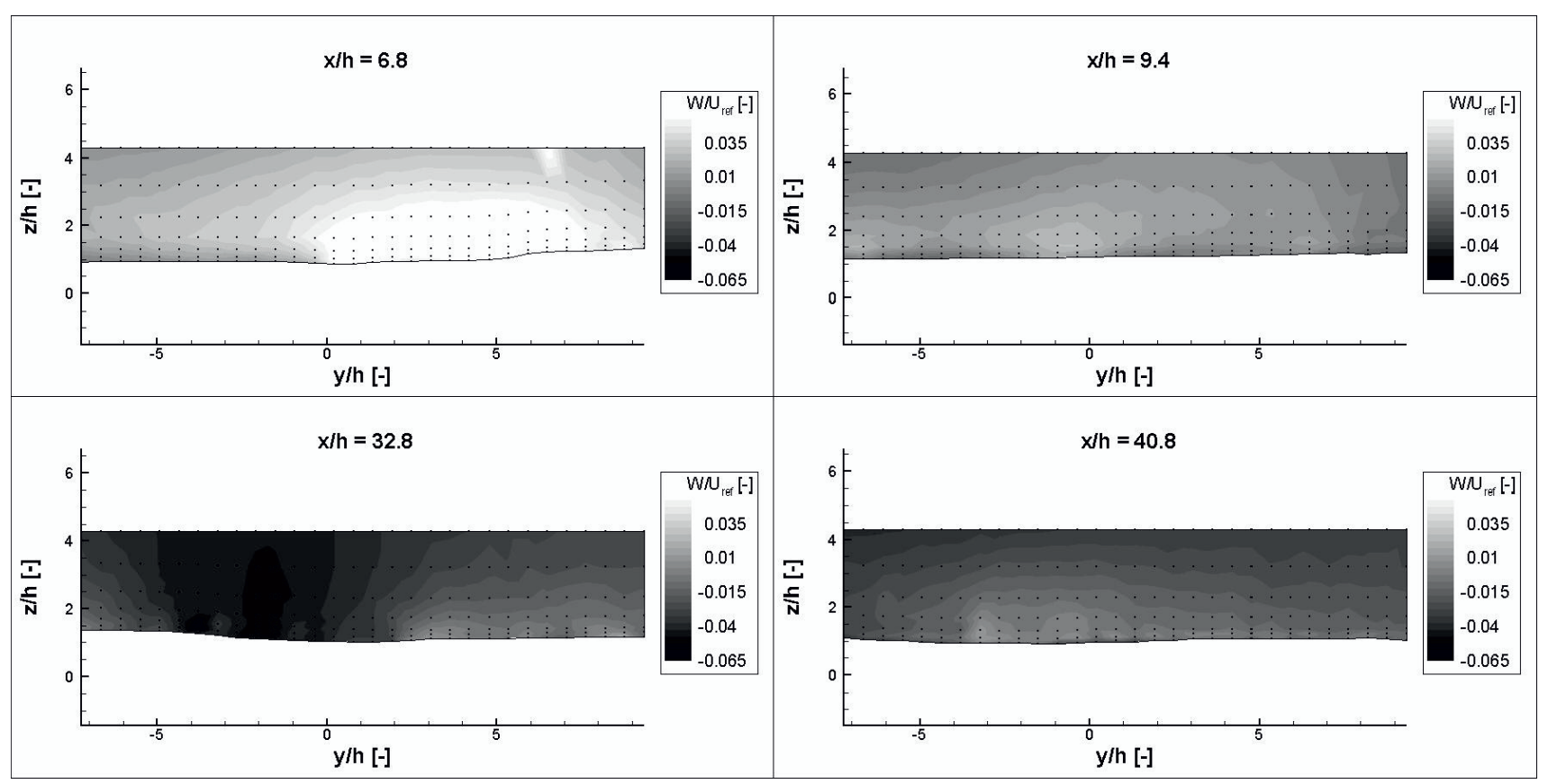

Figure 7. Mean dimensionless vertical velocities $w / u_{\text {ref }}$ at planes $y z$ (upstream view).
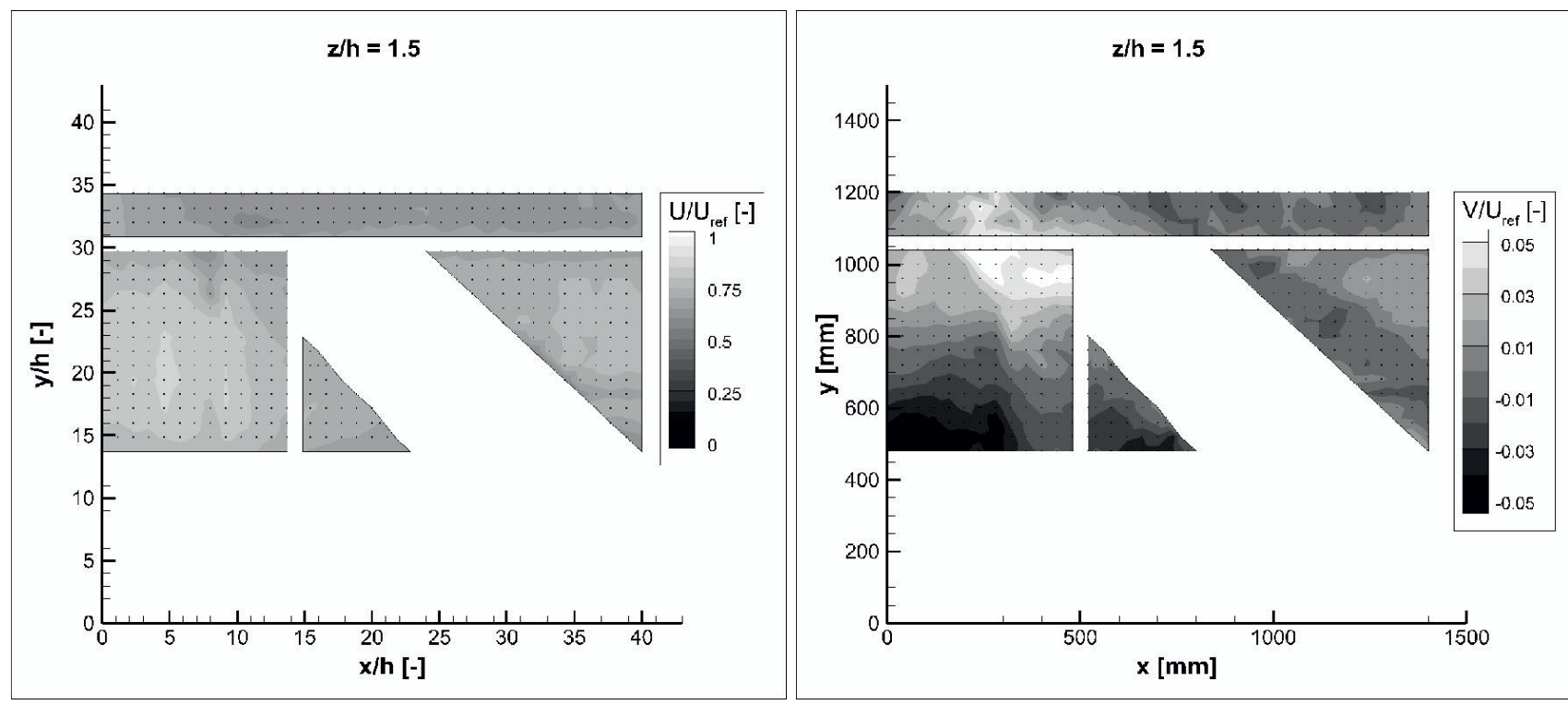

Figure 8. Mean dimensionless longitudinal velocity $u / u_{\text {ref }}$ (left) and dimensionless lateral velocity $v / u_{\text {ref }}$ (right) at dimensionless height $z / h=1.5$. The wind direction is from left to right. 


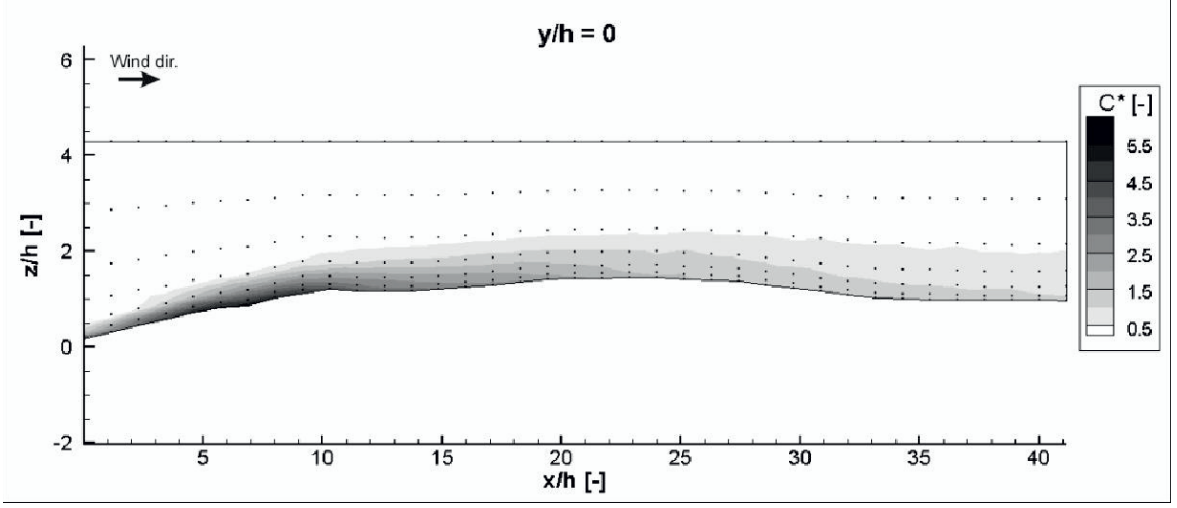

Figure 9. Mean dimensionless tracer gas concentrations $\mathrm{C}^{*}$ at vertical plane $x z$.

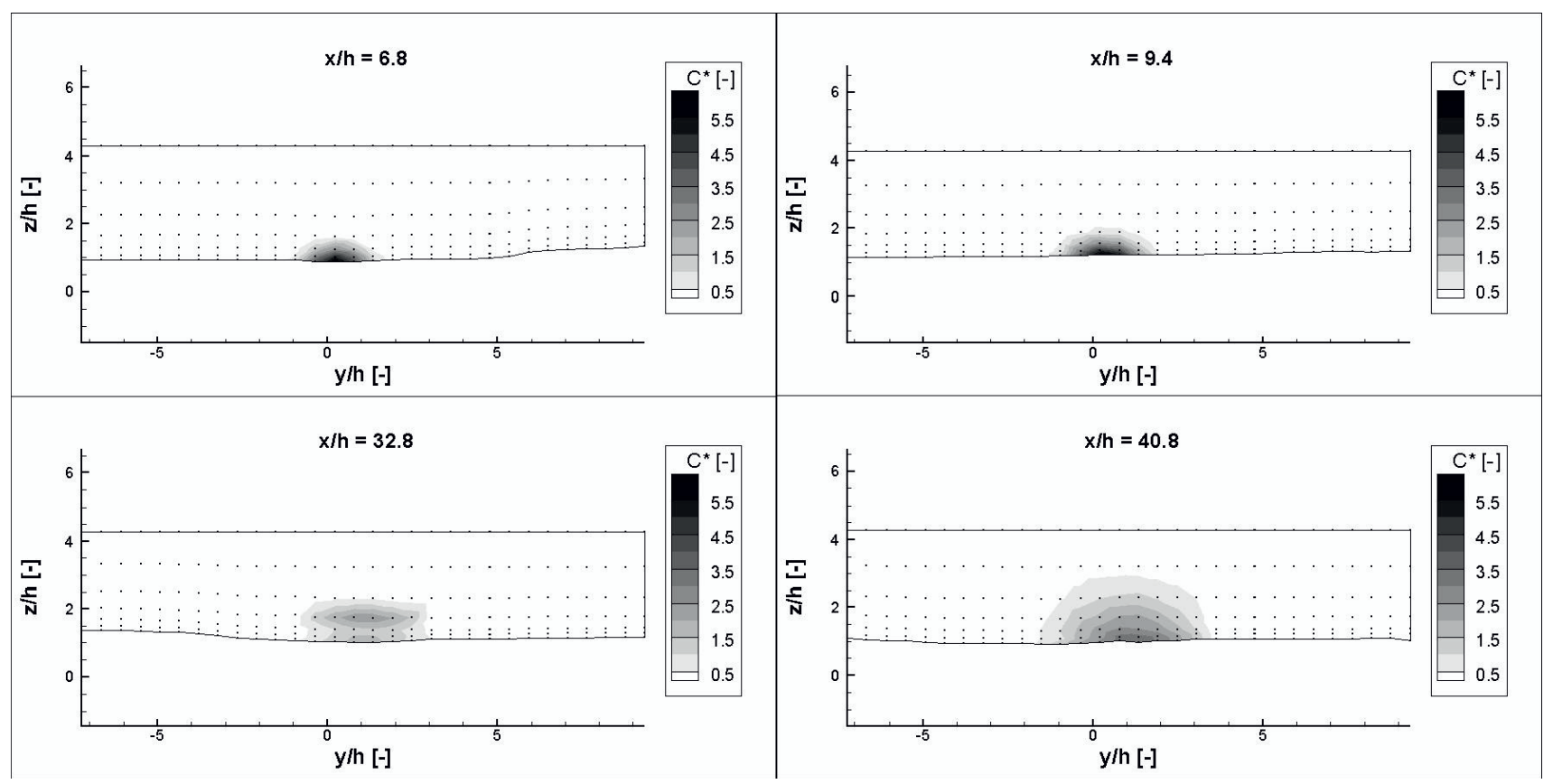

Figure 10. Mean dimensionless tracer gas concentrations $C^{*}$ at vertical planes $y z$ (upstream view).

\subsection{Concentration field}

In Figure 9 is presented the dimensionless tracer gas concentration $C^{*}=\left(C u_{r e f} H^{2}\right) / Q$ (where $C$ is measured volume concentration, $H$ is a vertical difference between the lowest and highest point in the model and $Q$ is source emission volume flow) at vertical plane $x z$. We can see that the highest values of $C^{*}\left(C^{*}>4\right)$ are kept within the coal mine excavation $(x / h<10)$. Behind the hill $(x / h>$ $30)$ the values of $C^{*}$ are at least four times lower $\left(C^{*}<1\right)$ than those in mine.

In Figure 10 the dimensionless tracer gas concentration $C^{*}$ is presented at four vertical planes $y z$. The plume extension can be observed at remoter planes, namely $x / h=32.8$ and 40.8 . At plane $x / h=32.8$ we can see the splitting of the plume into two plumes and at plane $x / h=40.8$ their merging. Furthermore, planes $x / h=$ $9.4,32.8$ and 40.8 demonstrates the shift of the plume centre from the contaminant source origin to the north direction (to populated area - Droužkovice village) by magnitude of one mine depth $(y / h=1)$. Both, splitting and shifting of the plume can be explained mainly by effect of the flow around the hill and terrain roughness (forested and populated areas). The shift can be explained as well by effect of "cornered" coal mine border on its northwest side.

\section{Conclusions}

The neutrally stratified flow over small scale model of open-cut coal mine including necessary surrounding topography and populated area was successfully performed in wind-tunnel. The simultaneous point measurements of two velocity components and concentrations revealed that the complex terrain topography and especially surface roughness has following effect on pollutant dispersion: 1) the highest concentration values were kept within the mine cavity; 2) the plume centre was shifted by magnitude of one mine depth to the north from point source origin. The main explanation of the plume shift could be the effect of the 
flow around the hill and occurrence of the forested and populated areas. In future work the neutrally stratified flow over the model concerning of planned mine expansion (the excavation should reach the middle part of recent simulated area - hill) will be simulated as well as gaseous pollutant positioned at the bottom of newly emerged mine. Hence, the impact of excavation transformation on pollutant dispersion can be observed.

\section{Acknowledgments}

Authors acknowledge financial support of project TA01020428 of Technology Agency of the Czech Republic. Author also would like to thanks to Environmental Wind Tunnel Laboratory working group in Nový Knín, Czech Republic. This work was carried out with institutional support RVO: 6138899.

\section{References}

1. V.S. Nikitin, N.Z. Bitkolov, p. 256 (1975)

2. X. Peng, G.R. Lu, J. of Wind Eng. and Ind. Aerodyn. 54/55, p. 473-481 (1995)

3. R. N. Meroney, C. Grainger, Symposium on Measurement and Modeling of Environmental Flows (1992)

4. S. Nosek, Z. Janour, K. Jurcakova, R. Kellnerova, L. Kukacka, Eur. Phys. J. 45, (2013)

5. L. Kukacka, S. Nosek, R. Kellnerová, k. Jurčáková, Z. Janour, The Scient.World J., p. 13 (2012)

6. VDI, Verein Deutscher Ingenieure (2012) 